\title{
President's Message: UX Thinking and the LITA Member Experience
}

\section{Rachel Vacek}

My mind has been occupied lately with user experience (UX) thinking in both the web world and in the physical world around me. I manage a web services department in an academic library, and it's my department's responsibility to contemplate how best to present website content so students can easily search for the articles they are looking for, or so faculty can quickly navigate to their favorite database. In addition to making these tasks easy and efficient, we want to make sure that users feel good about their accomplishments. My department has to ensure that the other systems and services that are integrated throughout the site are located in meaningful places and can be used at the point of need. Additionally, the site's graphic and interaction design must not only contribute to but also enhance the overall user experience. We care about usability, graphic design, and the user interfaces of our library's web presence, but these are just subsets of the larger UX picture. For example, a site can have a great user interface and design, but if a user can't get to the actual information she is looking for, the overall experience is less than desirable.

Jesse James Garrett is considered to be one of the founding fathers of user-centered design, the creator of the pivotal diagram defining the elements of user experience, and author of book, The Elements of User Experience. He believes that "experience design is the design of anything, independent of medium, or across media, with human experience as an explicit outcome, and human engagement as an explicit goal." 1 In other words, applying a UX approach to thinking involves paying attention to a person's behaviors, feelings, and attitudes about a particular product, system, or service. Someone who does UX design, therefore, focuses on building the relationship between people and the products, systems, and services in which they interact.

Garrett provides a roadmap of sorts for us by identifying and defining the elements of a web user experience, some of which are the visual, interface, and interaction design, the information architecture, and user needs. ${ }^{2}$ In time, these come together to form a cohesive, holistic approach to impacting our users' overarching experience across our library's web presence. Paying attention to these more contextual elements informs the development and management of a web site.

Let's switch gears for a moment. Prior to winning the election and becoming the LITA VicePresident/President-Elect, I reflected on my experiences as a new LITA member and before I became really engaged within the association. I endeavored to remember how I felt when I had joined LITA in 2005. Was I welcomed and informed, or did I feel distant and uninformed? Was the path clear to getting involved in interest groups and committees, or were there barriers that

Rachel Vacek (revacek@uh.edu) is LITA President 2014-15 and Head of Web Services, University Libraries, University of Houston, Houston, Texas. 
prevented me from getting engaged? What was my attitude about the overall organization? How were my feelings about LITA impacted?

Luckily, there were multiple times when I felt embraced by LITA members, such as participating in BIGWIG's Social Media Showcase, teaching pre-conferences, hanging out at the Happy Hours, and attending the Forums. I discovered ample networking opportunities and around every corner there always seemed to be a way to get involved. I attended as many LITA programs at Annual and Midwinter conferences as I could, and in doing so, ran into the same crowds of people over and over again. Plus, the sessions I attended always had excellent content and friendly, knowledgeable speakers. Over time, many of these members became some of my friends and most trusted colleagues. Unfortunately, I'm confident that not every LITA member or prospective member has had similar, consistent, or as engaging experiences as I've had, or as many opportunities to travel to conferences and network in-person. We all have different expectations and goals that color our personal experiences in interacting with LITA and its members.

One of my goals as LITA President is to enhance the member experience. I want to apply the user experience design concepts that I'm so familiar with to effect change and improve the overall experience for current members and those who are on the fence about joining. To be clear, when I say LITA member, I am including board members, committee members and chairs, interest group members and chairs, representatives, and those just observing on the sidelines. We are all LITA members and deserve to have a good experience no matter the level within the organization.

So what does "member experience" really mean? Don Norman, author of The Design of Everyday Things and the man attributed with actually coining the phrase user experience, explains that "user experience encompasses all aspects of the end-user's interaction with the company, its services, and its products." ${ }^{3}$ Therefore, I would say that the LITA member experience encompasses all aspects of a member's interaction with the association, including its programming, educational opportunities, publications, events, and even other members.

I believe that there are several components that define a good member experience. First, we have to ensure quality, coherence, and consistency in programming, publications, educational opportunities, communications and marketing, conferences, and networking opportunities.

Second, we need to pay attention to our members' needs and wants as well as their motivations for joining. This means we have to engage with our members more on a personal level, and discover their interests and strengths, and help them get involved in LITA in ways that benefit the association as well assist them in reaching their professional goals.

Third, we need to be welcoming and recognize that first impressions are crucial to gaining new members and retaining current ones. Think about how you felt and what you thought when you received a product that really impressed you, or when you started an exciting new job, or even used a clean and usable web site. If your initial impression was positive, you were more likely to connect with the product, environment, or even a website. If prospective and relatively new LITA 
members experience a good first impression, they are more likely to join or renew their membership. They feel like they are part of a community that cares about them and their future. That experience became meaningful.

Finally, the fourth component to a good member experience is that we need to stop looking at the tangible benefits that we provide to users as the only things that matter. Sure, it's great to get discounts on workshops and webinars or be able to vote in an election and get appointed to a committee, but we can't continue to focus on these offerings alone. We need to assess the way we communicate through email, social media, and our web page and determine if it adds or detracts from the member experience. What is the first impression someone might have in looking at the content and design of LITA's web page? Do the presenters for our educational programs feel valued? Does ITAL contain innovative and useful information? Is the process for joining LITA, or volunteering to be on a committee, simple, complex, or unbearable? What kinds of interactions do members have with the LITA Board or the LITA Staff? These less tangible interactions are highly contextual and can add to or detract from our current and prospective members' abilities to meet their own goals, measure satisfaction, or define success.

As LITA President, and with the assistance of the Board of Directors, there are several things we have done or intend to do to help LITA embrace UX thinking:

- We have implemented a Chair and Vice-Chair model for committees so that there is a smoother transition and the Vice-Chair can learn the responsibilities of the Chair role prior to being in that role.

- We have established a new Communications Committee that will create a communication strategy focused on communicating the LITA's mission, vision, goals, and relevant and timely news to LITA membership across various communication channels.

- We are encouraging our committees to create more robust documentation.

- We are creating richer documentation that supports the workings of the Board.

- We are creating documentation and training materials for LITA representatives to compliment the materials we have for committee chairs.

- We have disbanded committees that no longer serve a purpose at the LITA level and whose concerns are now addressed in groups higher within ALA.

- The Assessment and Research Committee is preparing to do a Membership Survey. The last one was done in 2007.

- We are going to be holding a few virtual and in-person LITA "Kitchen Table Conversations" in the Fall of 2014 to assist with strategic planning and to discuss how LITA's goals align with ALA's strategic goals of information policy, professional development, and advocacy.

- The Membership Development Committee is exploring how to more easily and frequently reach out, engage, appreciate, acknowledge, and highlight current and prospective members. They will work closely with the Communications Committee. 
I believe that we've arrived at a time where it's crucial that we employ UX thinking at a more pragmatic and systematic level and treat at it as our strategic partner when exploring how to improve LITA and help the association evolve to meet the needs of today's library and informational professionals. Garrett summarizes my argument nicely. He says,

"What makes people passionate, pure and simple, is great experiences. If they have great experience with your product [and] they have great experiences with your service, they're going to be passionate about your brand, they're going to be committed to it. That's how you build that kind of commitment."4

I personally am very passionate about and committed to LITA, and I truly believe that our UX efforts will positively impact your experience as a LITA member.

\section{REFERENCES}

1. http://uxdesign.com/events/article/state-of-ux-design-garrett/203, Garrett said this quote in a presentation entitled "State of User Experience" that he gave during UX Week 2009, a very popular conference for UX designers.

\section{2. http://www.jjg.net/elements/pdf/elements.pdf}

\section{3. http://www.nngroup.com/articles/definition-user-experience/}

4. http://www.teresabrazen.com/podcasts/what-the-heck-is-user-experience-design, Garret said this quote in a podcast interview with Teresa Brazen, "What the Heck is User Experience Design??!! (And Why Should I Care?)” 